\title{
On Dynamic Interactions Between Some Fish Resources and Cetaceans off Iceland Based on a Simulation Model
}

\author{
Gunnar Stefánsson, Jóhann Sigurjónsson and Gísli A. Víkingsson \\ Marine Research Institute, P. O. Box 1390, Skúlagata 4
}

121 Reykjavík, Iceland

\begin{abstract}
Twelve species of cetaceans are regarded as regular inhabitants in Icelandic and adjacent waters. Based on available estimates of the total food consumption of the cetaceans in the area, this paper explores potential interactions between three baleen whale species off Iceland and the relevant fish resources that constitute a part of their diet prey. The three species of whales are fin whale (Balaenoptera physalus), the largest cetacean consumer in this area, feeding mainly on krill (Meganyctiphanes norvegica) but also preying on some fish species like capelin (Mallotus villosus); minke whale (Balaenoptera acutorostrata), taking krill as well as a variety of fish, including capelin and gadoids (e.g. cod, Gadus morhua); and humpback whale (Megaptera novaeangliae) assumed to be feeding mainly on capelin.

The study is based on a variety of assumptions regarding stock sizes, food preference, potential rates of increase and harvesting strategies. A single-species model developed for investigating the effects of different utilization policies of the Icelandic cod stock is combined with a crude multispecies model and these are used to study the potential impacts on capelin and cod stocks by various developments of the whale stocks under consideration. A Pella-Tomlinson like model is used to describe the whale stocks. The population and fisheries dynamics for shrimp (Pandalus borealis) and capelin (both important food items for cod) are described using simple models. Thus, only aggregates such as total, recruiting or adult numbers or biomass are considered as opposed to the fully age-class based cod model.

The results indicate that both minke and humpback whales may have significant direct impact on the status of the capelin stock. The effects of fin whale predation on the capelin stock seems less significant unless such consumption occurs outside the sampled area, which is quite possible. The impact of the three baleen whale species on the development of the cod stock is uncertain, but may be considerable.
\end{abstract}

Key words: capelin, cod, Iceland area, food/feeding, harvesting strategy, multi-species interactions, whales

\section{Introduction}

In recent years increased importance has been attached to the role of species interactions in decisions on harvesting methods for individual marine species or complexes. This is reflected for example in recent multispecies-directed work in the North Sea (Anon., MS 1994), Boreal systems in general (Anon., MS 1991) and also specifically in the Barents Sea (Bogstad et al., 1997) and Icelandic waters (Pálsson and Stefánsson, MS 1997; Stefánsson et al., MS 1994; Danielsson et al., 1998).
Multispecies biological, assessment and harvesting models for Icelandic waters, have put emphasis on the cod-capelin interaction (Magnússon and Pálsson, 1989; 1991; Anon., 1995 MS a-d; Pálsson and Stefánsson, MS 1997). Recent work on biological management advice and economic considerations has also incorporated the cod-shrimp interaction (Stefánsson et al., MS 1994; Danielsson, et al., 1998). These considerations implied that a harvesting strategy for cod taking $25 \%$ of the fishable (i.e. 4+) biomass (possibly with a minimum catch level) would be beneficial in the medium term, even accounting for the predicted decrease in 
capelin and shrimp catches, possible density-dependence in cod growth, cod cannibalism and uncertainty in assessments, model assumptions and predictions. In particular it was found that the overwhelmingly important economic consideration was the rebuilding of the cod stock and catches. Based on these considerations, this harvesting strategy for cod was adopted by the Icelandic Government in 1995.

The above works on effects of harvesting strategies for fish stocks in Icelandic waters have not included the possible effects of other predators in the system, such as marine mammals. This is best done by including most of these factors in a single model. If each predator is considered separately, then the total effect of predation on prey catches cannot be determined since such a prediction will completely depend on the remaining mortality in the system; even if a predator consumes huge amounts of juvenile prey, a decrease in predator numbers may not result in major increases in catches of older prey if the amount consumed is minor compared to other predators.

Several species of cetaceans are regarded as regular inhabitants in Icelandic and adjacent waters. Based on available estimates of the total food consumption of the cetaceans in the area, it is possible to explore potential interactions between baleen whale species off Iceland and the relevant fish resources that constitute their principal prey. The three species of whales considered here are fin whale (Balaenoptera physalus), the largest cetacean consumer in this area, feeding mainly on krill (Meganyctiphanes norvegica) but also preying on some fish species like capelin (Mallotus villosus); minke whale (Balaenoptera acutorostrata), taking krill as well as a variety of fish, including capelin (Mallotus villosus) and gadoids (e.g. cod, Gadus morhua); and humpback whale (Megaptera novaeangliae) assumed to be feeding mainly on capelin.

For this reason, this paper incorporates predation on cod, capelin and Northern shrimp (Pandalus borealis) by whales and cod into a single model. The model is conceptually simple and in particular it does not incorporate such features as areal differences in overlap except through the estimation of consumption rates. The principle used throughout has been to take a commonly used population model for each species and incorporate that in the overall framework, rather than to take a uniform and symmetric model. This sacrifices some of the mathematical elegance of e.g. MSVPA (Anon., MS 1995d) but allows each population model to contain recognizable parameters commonly used for that species.

The paper compares various possible scenarios on how much the apex predators may consume of cod and capelin and how this may affect catches through changes in population abundance or cod mean weight at age.

\section{Methods}

A simulation model is used to investigate the possible variations in the combined population dynamics of apex predators, cod, capelin and shrimp. The principles are simply to use a regular age-based prediction model for the cod and simpler common models for other species. Each component is added in a fairly transparent fashion, so that it can be switched on or off for sensitivity evaluation.

\section{Population dynamics}

The model dynamics of the various populations will be described in the order implied by the trophic level.

\section{Whale population dynamics}

Minke whale. The population is assumed to change in accordance with the Pella-Tomlinson model, as described for example in Magnússon and Stefánsson (1988). The basic model described the population numbers in year $t+1$ by the equation:

$$
P_{t+1}=\left(P_{t}-C_{t}\right) S+(1-S)\left\{1+A\left[1-\left(\frac{P_{t-T}}{K}\right)^{Z}\right]\right\} P_{t-T}
$$

where $C_{t}$ and $P_{t}$ are the catch and population series, respectively. The parameters $A, z$ and survival, $S=\exp (-M)$, control the dynamics along with the age at maturation, $T$, taken as 5 years here and the carrying capacity, $K$. The natural mortality rate will simply be taken as $M=0.05$ throughout this paper, as has been commonly used in other studies. The parameters $A$ and $z$ can be cast in terms of the maximum sustainable yield rate (MSYR) and the corresponding population size, i.e. the maximum sustainable yield level (MSYL):

and

$$
M S Y L=\frac{1}{z+1}^{1 / z}
$$

$$
M S Y R=\left(\frac{1-S}{S}\right)\left(\frac{z}{z+1}\right) A
$$


Thus the dynamics of the minke whale population will be determined by the values of MSYR and MSYL. In the base case, MSYL will be taken to be 0.6 (conventional value for baleen whales, see Allen, 1980) and thus $z=2.39$. MSYR will be taken at $5 \%$ in base runs, but in stochastic runs MSYR will be considered in the range from 0 to $10 \%$. Sightings surveys give estimates of total abundance at a given point in time, and it is quite natural to use the depletion level at that time point, $P_{t} / K$, as a parameter, rather than the carrying capacity itself.

Humpback and fin whale. The dynamics of the humpback and fin whale are taken to be exactly the same as for the minke whale, with different values of some of the population-size parameters. In addition to the model assumptions listed above, there are indications that the current and historical increase in the humpback stock size can be of the order of $10 \%$ (Katona and Beard, 1990; Mitchell, 1975). As there has not been any whaling operation aimed at humpback whales for several decades, this stock should be well above MSYL and hence MSYR should be no less than the observed $10 \%$ increase. For this reason, it is of interest to investigate the effect of assuming MSYR $=10 \%$ in addition to other alternatives.

\section{Cod population dynamics}

Danielsson et al. (1998) considered only cod of age 3 and older. In this model, recruitment was taken to occur according to the Ricker model, but modified to account for potential cannibalism or competition by immature juveniles. In order to accommodate predation on pre-recruits, the age range has been extended down to age 1 (i.e. 1 January of the year after the year of birth).

Initial stock size and recruitment. The initial stock size and recruitment up to and including the 1994 year-class are determined from catches-at-age in numbers, survey and CPUE data as described in Anon. (MS 1995b), with uncertainty attached as described in Danielsson et al. (1998).

Natural mortality and recruitment of cod. Danielsson et al. (1998) described the stockrecruitment relationship with a function of the form initially developed by Pope and Woolner (MS 1981) and similar to the one used by Bogstad et al. (1993). The functional form is given by

$$
R=\alpha S e^{-S / K} e^{-\varsigma J}
$$

where $R$ denotes 3-year old recruits, $S$ spawning stock biomass, $J$ the biomass of immature cod available as cannibals at the time of birth of the yearclass in question and $\zeta$ and $K$ are constants to be estimated. For $J$, an index of the biomass of age $2+$ cod was taken as a measure of potential cannibals. In Stefánsson and Steinarsson (1993) it is shown that there is a good relationship between the indices of abundance from the 0-group survey in August and the 1-group survey in March of the following year. There are also indications that there is a poorer relationship between the abundance of 1 group in March and age 2-group in March of the following year. There is, however, a very good relationship between the 2-group survey index and the 3-group recruitment estimate from VPA (Stefánsson, MS 1992).

Bogstad et al. (1994) also found that the possible cannibalism seemed mainly to occur by older, immature cod on the youngest after the 0-group survey. The above further indicates that this mortality is most likely to occur in the 1-group stage and not thereafter.

In all, this indicates that a plausible model of the recruitment process is to generate 1-group stock abundance by:

$$
N_{1}=\alpha^{\prime} S e^{-S / K}
$$

and to reduce these according to natural mortality due to cannibalism on the 1-group by:

$$
N_{2}=N_{1} e^{-M_{1} 1,1} e^{-\varsigma J}
$$

Here, the revised constant, $\alpha$, is increased from $\alpha$ in order to account for natural mortality other than cannibalism during the 1 -group stage. $M_{1,1}$ is used to denote this natural mortality at the 1 -group stage and is set at 0.2 in simulations without marine mammals, as is the base natural mortality, $M_{a, 1}$ on all other age groups, $a$.

For all age groups of cod, the natural mortality is also connected to the possible predation by apex predators. Thus, the total natural mortality is written as:

$$
M_{a}=M_{a, 1}+\sum_{\text {pred }} M_{a, 2}^{\text {pred }}
$$

The mortality, $M_{a, 2}^{\text {pred }}$, generated by each predator is produced in the model by taking a base induced mortality and scaling it with the relative size 
of the apex predator population in the present year to the reference period. For simulations with marine mammals, the mortality in the reference year is defined by fixing $M_{a}=0.2$ and setting $M_{a, 2}$ for each predator such to obtain the estimated consumption. Thus a doubling in predator population size will double the natural mortality inflicted by the predator. The other side of the coin is that a doubling of the cod stock will double the estimated consumption of cod by the predators.

Although some odontocete cetaceans have been found to eat gadoids in Icelandic waters (Sigurjónsson and Víkingsson, 1997; Martin and Clarke, 1986; Víkingsson and Sigurjónsson, MS 1996), these are not included in the present model. Thus, only minke whales are included as direct predators of cod.

In addition to the above dynamics, Steinarsson and Stefánsson (MS 1991) found relationships between the abundance of capelin and the mean weight-at-age of cod. Thus, a reduction in the biomass of capelin, from fishing or predation, is likely to have an effect on the harvest of cod through a reduction in the mean weight-at-age. This effect is regularly included in assessments (Anon., MS 1995b), has been included in other medium-term predictions and the effect will be included here in order to investigate the potential indirect effect of capelin predation on the cod harvest.

\section{Capelin population dynamics}

Apart from natural mortality, the same dynamics are used for capelin as in Danielsson et al. (1998). The model is a simplistic description of the capelin stock, where the generated number of 1 -group recruits in year $t-1$ enter the fishery as 2 -group in autumn of year $t$ to spawn and die at age 3 in year $t+1$.

Capelin recruitment. As in Danielsson et al. (1998), capelin recruitment is taken to be cyclic (with an unknown period in stochastic simulations) to simulate the stock crashes observed in the past decades (Vilhjálmsson, 1994). The actual level of recruitment is based on the average value on 1 August, derived from acoustic measurement (Vilhjálmsson, 1994) and base level consumption estimates by the various predators as described below. Thus one obtains a recruitment biomass level along with a biomass level at the start of the fishery. All predation is assumed to take place between these two time points.
Capelin natural mortality. Danielsson et al. (1998) assumed natural mortality for capelin to occur during a 12-month period before recruitment to the fishery. Natural mortality during the fishing season (September-March) has been estimated to have been on average 0.035 per month (Vilhjálmsson, 1994) for recent years. No other estimates of natural mortality are available and hence this estimate has been used for other time periods as well.

Natural mortality and increases in weight-atage have been found to roughly cancel during the winter months when the fishery takes place (Vilhjálmsson, 1994) and therefore the winter natural mortality is omitted from the computations and changes in mean weight-at-age are also omitted.

In earlier projections, Danielsson et al. (1998) simply scaled the estimated value of winter natural mortality according to changes in the size of the spawning stock biomass of cod and applied the scaled value to an assumed 12-month pre-recruit period. This is equivalent to assuming that cod is the overwhelming cause of natural mortality for capelin and that the influence of the cod is exerted before the fishing commences.

The present paper changes this assumption of natural mortality scaling and replaces it with a model where the capelin natural mortality is composed of a component for each of the predators, cod, minke whale, fin whale and humpback whale, respectively. Thus, the total amount consumed by all these predators is taken as the full source of natural mortality just prior to fishing. Adding up the total amount consumed and adding this amount to the average abundance at the start of the fishery yields an estimate of the total abundance of capelin available prior to predation or fishing. Since the model is a single year-class model, this is also the initial recruitment. The induced natural mortalities now correspond a simple log-ratio of the prior-toposterior abundance, i.e. the log-ratio of the recruitment to the biomass at the start of the fishery is an estimate of the total pre-recruit natural mortality and this is separated into components according to the point estimate of consumption by each predator.

\section{Shrimp population dynamics}

The shrimp population dynamics are taken unmodified from Danielsson et al. (1998). Notably, consumption of shrimp by apex predators is ignored in the simulations presented. Thus, shrimp biomass 
changes from one year to the next through the previous biomass plus recruitment minus catch and consumption by cod, in a simple additive biomass model.

The cod consumption is based on a model estimated in Stefánsson et al., (MS 1994a), where the biomass of shrimp is reduced by an amount proportional to the biomass of immature cod. The annual recruitment (in biomass) of shrimp is given as a function also of the immature cod biomass, since a negative relationship has been found between the two (Stefánsson et al., MS 1994a).

\section{Relating Available Numerical Data to the Model}

\section{Consumption}

Assumptions regarding the amount and type of food taken by each of the whales species involved are based on Sigurjónsson and Víkingsson (1997) estimates of consumption by area and species using their 'method A' in all cases. The basic inputs in their calculations are estimates of absolute abundance (based on systematic sightings surveys), estimated migratory cycle for each species, average weight of individual whales, estimated energy requirement per individual and the food consumption as found by direct sampling or by other means. Based on these findings, the capelin consumption of the humpbacks, fin and minke whales and the cod consumption of the minke whales is as outlined below.

Humpback whale. During the winter capelin fishery north of Iceland, humpback whales are frequently reported around fishing vessels taking capelin (Sigurjónsson and Gunnlaugsson, 1990). Also, the humpback whale is frequently sighted close to the capelin concentrations off the northwestern clockwise to the eastern coasts of Iceland during the summer season, e.g. during the 1995 sightings surveys (June-August), where major concentrations occurred in this area (Marine Research Institute, Iceland, unpubl. information). The northerly areas are juvenile grounds for capelin, but the adult capelin also occupies this area during the spawning migration from Jan Mayen to the southern coast of Iceland (Vilhjálmsson, 1994). In absence of stomach samples and in light of these observations and observations from other areas, Sigurjónsson and Víkingsson (1997) assumed that $60 \%$ of the humpback diet around Iceland is fish and the remaining $40 \%$ planktonic krill. Judging from visual observations, capelin appears to be the dominant fish prey of the humpback whale in Icelandic waters (Marine Research Institute, Iceland, unpubl. information). Assuming that the fish component of the humpback whale diet consists entirely of capelin, the annual consumption of capelin is around 119000 tons, which is the value applied here.

Minke whale. Using relative frequencies of identified food items in minke whales stomachs (Sigurjónsson and Galan, MS 1990), capelin comprises $27.7 \%$ of the diet in Icelandic coastal waters. Two alternative estimates of the capelin consumption by minke whales are available; i.e. one that only refers to the Icelandic coastal waters within the continental slope and amounts to 576000 tons, and the other amounting to 608000 tons, that also covers the waters along the East Greenland coast, that is, the main area of the Icelandic capelin stock. The latter will be used here since it this is based on a more extensive description of the areal distribution of the two species.

The minke whale is apparently the only one of the species of whales here considered that consumes significant amounts of cod. Approximately $6.1 \%$ (by frequency) of the animals sampled in the coastal waters around Iceland was large teleost fish species (Sigurjónsson and Galan, MS 1990). Since cod is by far the largest stock of large teleosts occupying the shelf areas around Iceland, the following calculations will be based on the assumption that a large proportion of this consumption by the minke whale consists of cod. Taking only the shelf area, $6.1 \%$ of Sigurjónsson and Víkingsson (1997) estimate of 2081000 tons gives approximately 127000 tons. If this is all to be cod, the natural mortality on cod induced by minke whales is more than that usually assumed to affect the cod stock, i.e. $M=$ 0.2 , and there are certainly more natural causes of cod deaths than merely consumption by minke whales. As a base case, therefore, it will be assumed that half of the large teleost fishes consumed by minke whales are cod. This implies a base-case consumption of some 60000 tons of cod by the minke whale and a natural mortality of about 0.1 inflicted by the minke whale. Thus, the total natural mortality of $M=0.2$ is split into two equal parts, one due to consumption by minke whales at their current (1995) population size and one part due to other natural causes. If the size of the stock of minke whales increases then the corresponding 
natural mortality inflicted on cod will be assumed to increase when this consumption is included in the model. Of course when marine mammals are not included in the model, then $M=0.2$ will be assumed for cod throughout the simulations. Thus the difference between these two runs will merely be due to the simulated change in the whale stocks from the base stock size.

The effect of this on the cod stock and fishery will depend on what age groups of cod the minke whale is assumed to prefer. The base-case assumption used here is that the minke whale has a uniform selection pattern for cod age 1 and older. The actual scaling multiplier is set so that the amount consumed by the minke whale in the model in 1994 is close to the estimated value, implying an induced $M$ value of 0.11 . An alternative scenario is also considered, where the minke whale selects older cod, not selecting age groups 1-3, fully selecting all ages 5 and older but $1 / 2$ of full selection on age group 4, inducing $M=0.16$ on older fish, i.e. most of the total $M$ of 0.20 .

There is considerable uncertainty surrounding this consumption estimate (Sigurjónsson and Víkingsson, 1997) and in base-case stochastic simulations it will be assumed that the actual consumption of cod by minke whales inflicts a natural mortality between zero and twice the base number of 0.1 .

Fin whale. The total consumption of capelin by fin whales in the main capelin area as defined above is some 63000 tons annually, assuming Sigurjónsson and Víkingsson (1997) estimate of $2.4 \%$ capelin in the fin whale diet. That figure will be used as a base-case assumption in this modeling exercise. However, as discussed by Sigurjónsson and Víkingsson (1997), the sampling in Iceland took place west and southwest of Iceland, where euphausiid crustaceans are abundant and during only part of the year. Since fin whales often take fish as an important second prey choice in other North Atlantic areas (Sigurjónsson, 1995) and as main prey in others (capelin comprised $80-90 \%$ of the diet in Newfoundland (Mitchell, 1975)), one alternative hypothesis that some $30 \%$ of the fin whale diet consists of capelin will be considered here. This would correspond to an annual consumption of about 780000 tons of capelin.

Cod. The cod stock is a considerable capelin predator (Pálsson, 1983) and typical estimates of the consumption of capelin by cod in specific months have been in a range which may correspond to an annual consumption in the range 0.51.0 million tons (Magnússon and Pálsson, 1989). It is not clear how this consumption should be separated into capelin pre-recruits, the fishable stock and dying post-spawners. For the base model, a value of 500000 tons will be used for the consumption of prerecruit capelin by cod, and an alternative assumption of 1 million tons will also be considered.

Using the base-case numbers, the above indicates that the total consumption of capelin by the modeled predators may have been about 1.3 million tons per annum in recent years. Since the average capelin adult biomass in autumn during 198393 was estimated at around 1.4 million tons (Vilhjálmsson, 1994), this implies that the total biomass before the consumption by predators in the model may have been about 2.7 million tons, implying a natural mortality of about 0.054 per month. This natural mortality can then be separated into mortality induced by the various predators by using the relative consumption by each one. The results are detailed in Table 1.

It should be noted that this particular approximation in respect to the real world, lumps several processes into one. In particular, the consumption is converted to a base-case natural mortality in a fashion which is equivalent to assuming that the consumption of capelin by its predators occurs in autumn, just before the start of the fishing season, but after the main growth period of capelin. Furthermore, the modeling approach of scaling natural mortality with the size of the predator stock will of course imply that a doubling of the predator stock during a simulation doubles the natural mortality of the prey, but not the amount consumed. Similarly, a doubling of the prey stock size doubles the consumption by each predator.

\section{Population dynamics parameters}

The parameters controlling the base-case population dynamics of the apex predators are given in Table 2 where bounds and CVs are also given for some of the parameters. For stochastic simulations, the bounds are used by assuming a uniform distribution of the associated parameter, and the $\mathrm{CV}$ is used as a standard error in a lognormal distribution. In this table, $\mathrm{K}$ is determined from the initial stock size in 1995 (Sigurjónsson and Víkingsson, 1997) along with the depletion level. Thus, bounds 
TABLE 1. (a) Consumption of capelin by modeled predators with corresponding induced natural mortality in base-case and consumption assumed in alternative models. (b) Development of biomass in a typical year.

\begin{tabular}{lccc}
\hline \hline Predator species & $\begin{array}{c}\text { Base-case Consumption } \\
\text { ('000 tons) }\end{array}$ & $\begin{array}{c}\text { Induced Mortality } \\
\text { per Month }\end{array}$ & $\begin{array}{c}\text { Alternative Consumption } \\
\text { ('000 tons) }\end{array}$ \\
\hline Minke & 608 & 0.026 & 576 \\
Fin & 63 & 0.003 & 784 \\
Humpback & 119 & 0.005 & 1.000 \\
Cod & 500 & 0.021 & \\
Total consumed & 1290 & 0.054 &
\end{tabular}

Biomass development

$\begin{array}{lr}\text { Recruiting biomass } & 2690 \\ \text { Consumption } & 1290 \\ \text { Pre-fishing biomass } & 1400 \\ \text { Typical catch } & 1000 \\ \text { Residual SSB } & 400\end{array}$

TABLE 2. Input parameter values in base-case. Also given are bounds $(L=$ Lower, $C=$ Center, $U=$ Upper) for stochastic simulations.

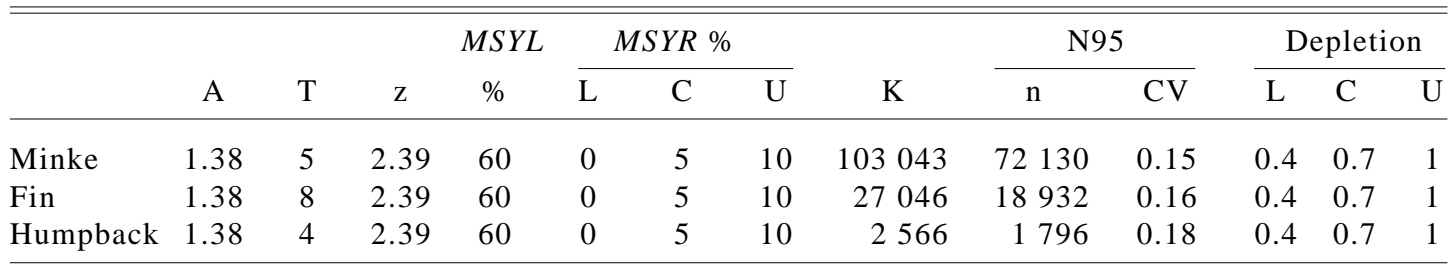

on the depletion level imply bounds on the maximum stock size.

The initial state of the stock (before 1995) in the model is set constant (as in the N95-columns) so that the recruitment function can be initiated with the time lag according to the age-at-maturity $(T)$, starting in 1995.

\section{Harvesting strategies}

In order to simulate population trajectories, some assumptions have to be made about the conduct of fishing into the future. For some of the stocks considered there is a documented rule describing how catches are taken from the stocks (cod and capelin), whereas for others there is no fixed rule and for some there is a de facto rule.

The currently implemented catch control law for capelin is to attempt to leave 400000 tons for spawning and this rule is therefore used in the simulations. Following work described in Baldursson et al. (1996) and Danielsson et al. (1998), a catch control law was adopted for cod in Icelandic waters. The adopted catch control law is to catch $25 \%$ of the biomass of cod of age 4 and older. In addition, a run-in period with a minimum catch was used in practise (but not in the simulations) and an upper bound of 450000 tons is formally placed on the catches. No formal catch control law is in place for shrimp, but the modeled catch control law for shrimp is to harvest the sustainable yield. As there is at present no harvest of marine mammals, the simulations do not include any such catches.

\section{Results and Discussion}

\section{Initial simulations and sensitivity analyses}

Four scenarios with respect to the consumption of capelin and cod by whales are considered for the purpose of initial analyses: 


\begin{tabular}{llcc}
\hline & & \multicolumn{2}{c}{ Cod consumption } \\
\cline { 3 - 4 } Predation by apex predators & & Included & Omitted \\
\hline Capelin & Included & A (Base-case model) & B \\
consumption & Omitted & C & D \\
\hline
\end{tabular}

Scenario A includes all the various apex predation components, described above as the "base case", whereas scenario D mimics the analyses in Danielsson et al., (1998) albeit with slight modifications in parameter values in lieu of assessment results given in Anon. (MS 1995b) and Anon. (1995c).

Starting dates for different pieces of the simulation vary a bit, since a run-in period is required for the Pella-Tomlinson model, whereas the most recently available 1995 cod assessment of Anon. $(1995 b)$ is used as a starting point for the cod simulations, and hence the years prior to 1995 are run-in years for cod, used to produce recruitment and cannibalism. Starting in 1996 all parts of the model are true simulations.

Deviations B-D from the base-case model A are implemented simply by omitting completely the corresponding facet of the model. Thus, when consumption of capelin by apex predators is omitted, this leads to a revision of recruitment and allocation of all prerecruit natural mortality to cod only.

In addition to these simulations, further deviations were considered:

- E: As in base-case simulation, except fin whales consume some 780000 tons of capelin

- F: As in base-case simulation, except cod consume 1 million tons of pre-recruit capelin

- G: More accurate knowledge on the depletion level (uniform in range 0.6-0.8 rather than 0.4-1.0)

- H: More accurate abundance data (CV half of base-run)

- I: More accurate estimates of MSYR (0.040.06 in place of $0-0.1$ )

- J: Exact knowledge of apex stomach content data on capelin (CV on inflicted $\mathrm{M}$ set to 0.01 in place of 0.25 )

- K: Exact knowledge of minke stomach content data on cod (fixed at $3 \%$ rather than uniform from 0 to $6 \%$ )
- L: Increased MSYR to 10\% for humpback whales

- M: Minke whale selection pattern for cod bent towards older fish

The simulation can be conducted as a deterministic simulation where the model is computed forward in time without stochasticity and all variables are simply set to their expected value. Results regarding cod catches from two such simulations are shown in Fig. 1 which depicts the trend in yield in the two particularly interesting cases, A and D. This figure contrasts the expected catches when the whales are included at base-case levels with the expected catches when the apex predators are completely omitted from the model.

Similar results for the spawning stock biomass (SSB) are shown in Fig. 2. It is seen that the curves are at lower levels in scenario A, which is reasonable given that the minke whale is assumed to consume considerable amounts of cod per annum and that the minke whale stock is expected to increase during the forthcoming decades since it is below carrying capacity $(K)$ in the model. The implication of this is that a prediction made while omitting the apex predators will be too optimistic, so that if $(D)$ is used as a model but $(A)$ is closer to reality, then the long-term utilization of the cod stock will result in lower catches than predicted.

In particular, the evaluations in Danielsson et al. (1998), which were used as a basis for the choice of a management procedure for cod, may indicate long-term catches of cod which are over $20 \%$ too high. Naturally this follows from the increased total mortality on the cod stock, which leads to an "equilibrium" at a lower stock size and lower productivity than in D. This particular effect is illustrated in Fig. 3. The "equilibrium" cod catch as a function of cod biomass is computed by projecting the system forward using a fixed fishing mortality for cod and computing an average at the end of the time period (there is no true fixed equilibrium due to the cycles in the capelin stock). The catch control law for cod is also shown (straight line), as is the predicted path from the 1993 level towards "equilibrium". 


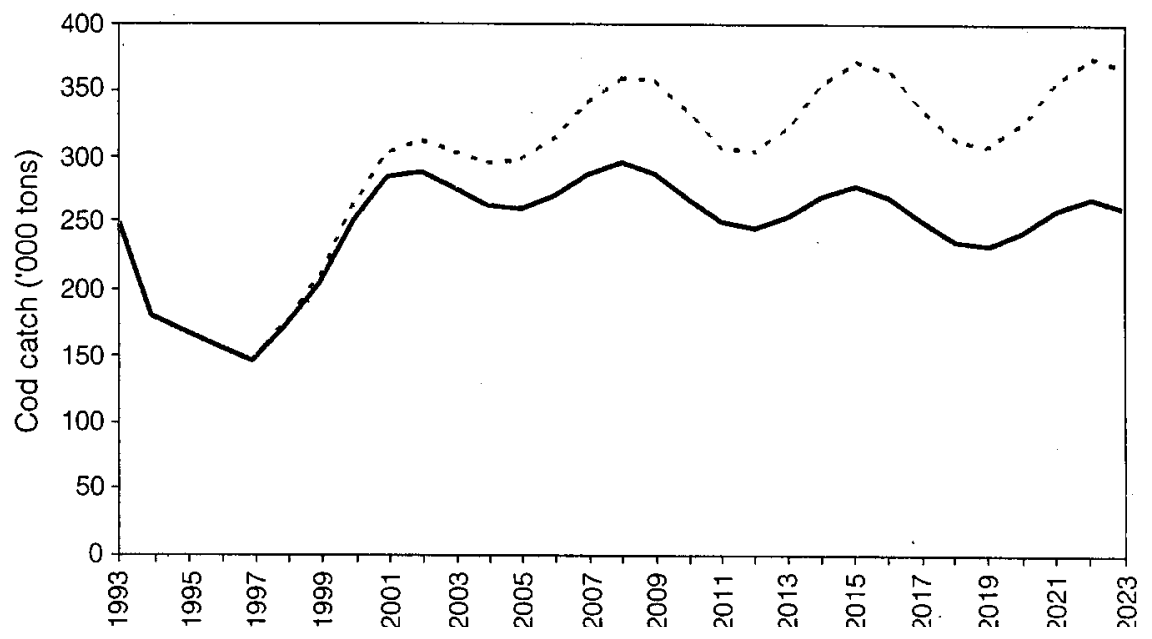

Fig. 1. Trends in cod catches in base case scenario (A) with marine mammals (solid line) and alternative scenario (D) without marine mammals (dashed line).

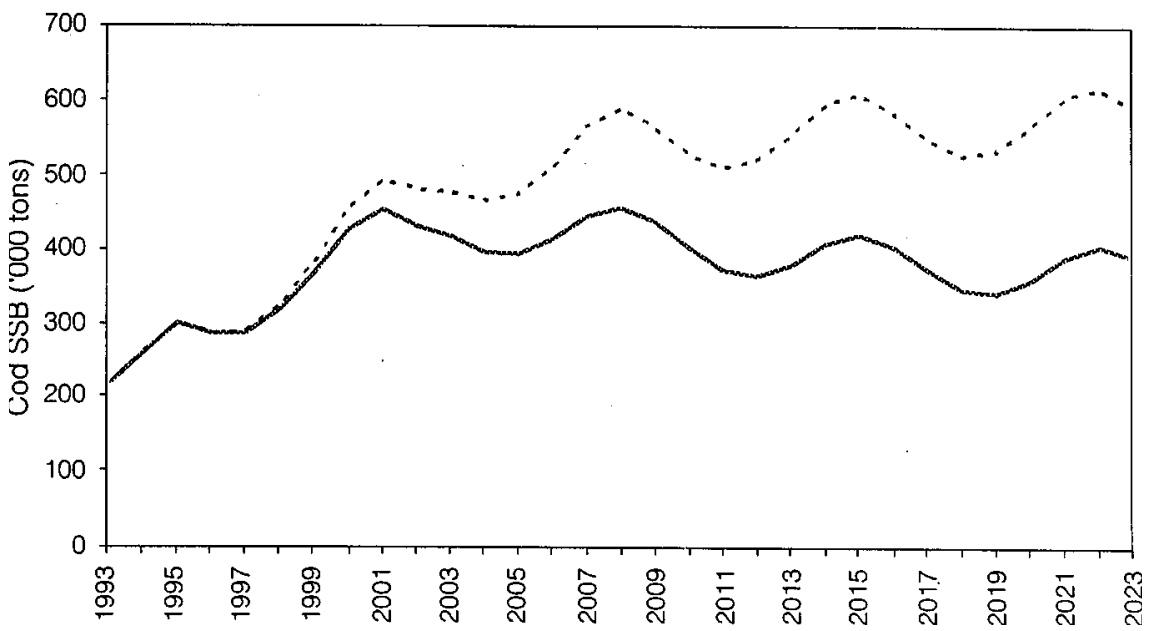

Fig. 2. Trends in cod spawning stock biomass in base case scenario (A) with marine mammals (solid line) and alternative scenario (D) without marine mammals (dashed line).

Figure 4 also shows the "equilibrium" curve for scenario A. It is seen how the catch control law intersects the "equilibrium" curve at a lower catch and stock level in scenario A than in D. It is clearly seen from the above, how predictions based on a model excluding the whale stocks may lead to a bias in the expected catch levels. The extent of the bias depends on the assumptions of the model. Some of these assumptions are based on detailed knowledge, whereas others have considerable uncertainty attached to them. Thus, alternative scenarios can be argued, which will increase the difference between the "equilibrium" curves or make them closer. This is a basic problem which is inherent in making de- terministic projections without taking uncertainty into account.

Alternatively, simulations can be conducted in a stochastic fashion by selecting a set of random values from the distributions assigned to each uncertain variable. The stochastic simulations are conducted by running 100 such simulations. Although it would be possible to encompass all the uncertainty and variation listed in the various scenarios into one stochastic simulation, some of these variations can better be considered using completely alternative models. Some of the more important output values are contrasted in Table 3 . 
Since the model exhibits some cyclic behavior, an average of several years (2016-2023) is used for comparisons.

It is seen that the major factor affecting the result on cod yield is the predation by minke on cod (A versus B). It is also seen that assuming increased consumption of capelin by fin whale (A versus $\mathrm{E}$ ) has the effect of decreasing the predicted capelin catch. The range from 0 to maximum fin whale consumption of capelin (C versus $\mathrm{E}$ ) corresponds to a reduction of the capelin catch by some 100000 tons.
Since the present model includes shrimp as cod prey, but this prey does not occur also as a prey to the whales, the effect of incorporating whales in the model is to increase future catches of shrimp, as is to be expected. This is illustrated in Fig. 5.

An important additional concern is the effect of the uncertainty in the whale stocks on the variance in predictions. It is seen that the variability in apex predation is reflected as an increase in the standard error of cod yield from 32 to 85 or by over $250 \%$. The CV in cod yield thus changes from below

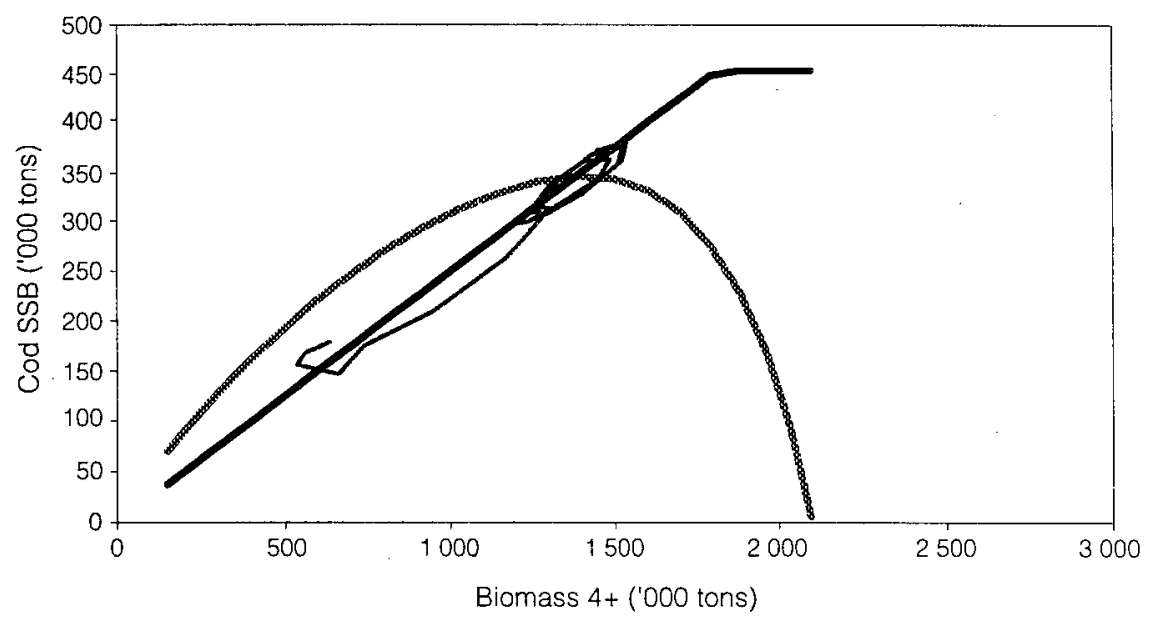

Fig. 3. Catch control law for cod (solid, straight) as a function of the biomass of cod, age 4 and older, "equilibrium" curve and projected trajectory (thin) under scenario D.

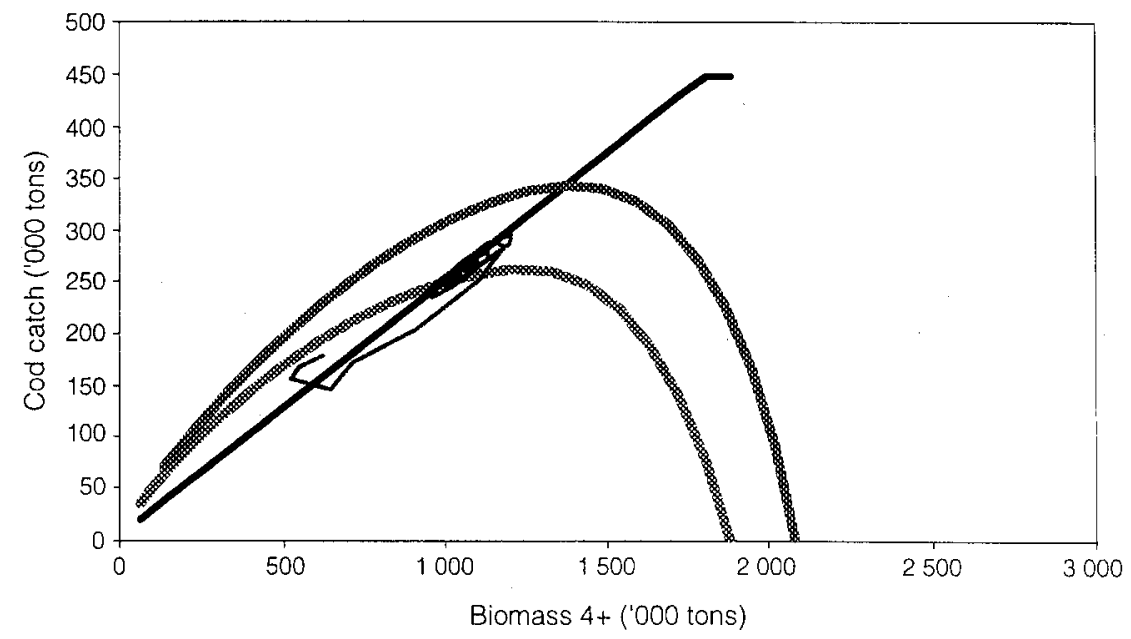

Fig. 4. Catch control law for cod (solid, straight) as a function of the biomass of cod, age 4 and older, A (low) and D (high) "equilibrium" curves and projected (thin) trajectory under A. 
TABLE 3. Resulting average cod biomass, cod catches and capelin catches in final simulation years. Statistics (average and standard deviation) are based on 100 simulations.

\begin{tabular}{|c|c|c|c|c|c|c|c|}
\hline & \multicolumn{2}{|c|}{ Cod biomass } & \multicolumn{2}{|c|}{ Cod catch } & \multicolumn{2}{|c|}{ Capelin catch } & \multirow[b]{2}{*}{ Notes } \\
\hline & Average & Std. d. & Average & Std. d. & Average & Std. d. & \\
\hline A & 1064 & 358 & 262 & 87 & 641 & 179 & Base case \\
\hline $\mathrm{B}$ & 1381 & 148 & 339 & 32 & 587 & 167 & No predation on cod \\
\hline $\mathrm{C}$ & 1116 & 336 & 274 & 80 & 701 & 155 & No apex predation on capelin \\
\hline $\mathrm{D}$ & 1406 & 156 & 344 & 31 & 645 & 154 & No apex predation \\
\hline $\mathrm{E}$ & 1049 & 330 & 259 & 82 & 612 & 183 & Increase consumption of capelin by fin whale \\
\hline $\mathrm{F}$ & 1072 & 303 & 266 & 75 & 637 & 160 & Increase consumption of capelin by cod \\
\hline $\mathrm{G}$ & 1079 & 267 & 267 & 67 & 658 & 157 & More accurate information on depletion \\
\hline $\mathrm{H}$ & 1064 & 327 & 263 & 80 & 649 & 158 & More accurate survey data \\
\hline I & 995 & 343 & 247 & 86 & 636 & 155 & More accurate information on $M S Y R$ \\
\hline $\mathrm{J}$ & 1061 & 404 & 259 & 96 & 646 & 158 & No error in apex stomach content data on capelin \\
\hline $\mathrm{K}$ & 1076 & 300 & 266 & 73 & 647 & 150 & No error in minke cod stomach data \\
\hline $\mathrm{L}$ & 1069 & 346 & 263 & 83 & 645 & 151 & Increased $M S Y R$ by humpback \\
\hline M & 1131 & 233 & 280 & 59 & 647 & 159 & Move minke sel. Pattern to older cod \\
\hline
\end{tabular}

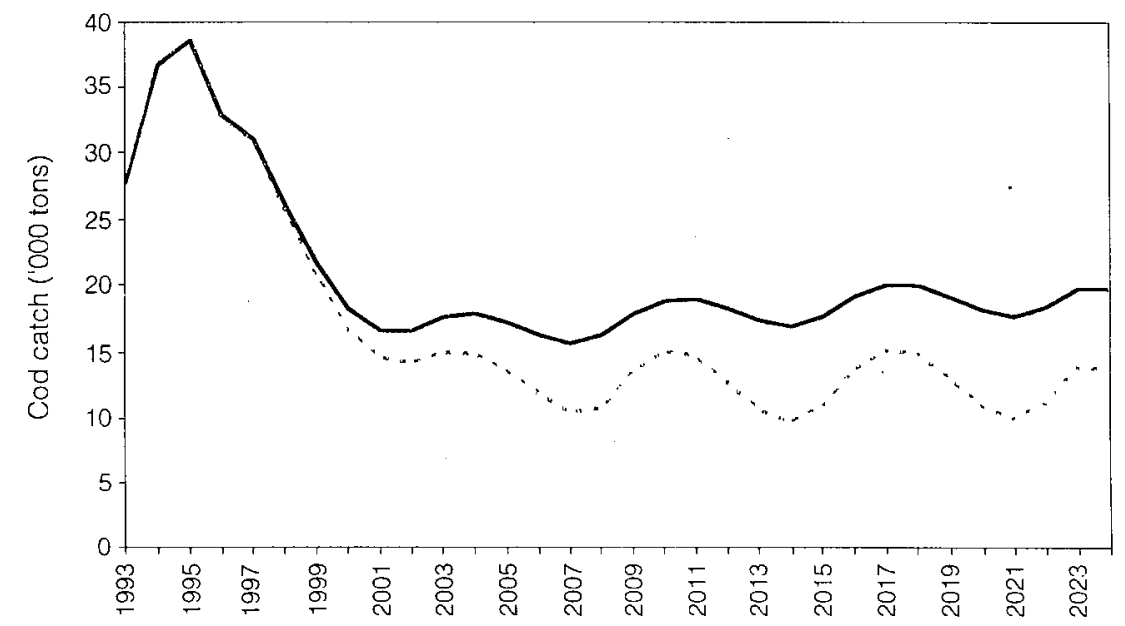

Fig. 5. Development of shrimp catches in base case scenario (A) with marine mammals (solid line) and alternative scenario (D) without marine mammals (dashed line).

$10 \%$ to some 30\%. This effect is depicted in Figs. 6 and 7 which summarize the probability distribution of future catches in terms of $5 \%, 25 \%, 50 \%, 75 \%$ and $95 \%$ percentiles along with 5 sample trajectories. It is seen that the median catch is lower in Fig. 6 , and although the upper bound is the same, the lower bound is lower, reflecting the increased variance in the results due to the uncertainty in the whale consumption.

As for capelin, it is seen that the sort of variation encountered when considering the whale stocks is a relatively minor change in expected capelin yield from the base case $(A)$ to the case when marine mammals are not included. The standard deviation only exhibits a minor increase, however. Naturally, there is a considerable compensation in this model system since the reduced consumption of cod by marine mammals leads to an increased consumption of capelin by cod.

The variation and uncertainty described above can be considered from several viewpoints. One issue is clearly the effect of different assumptions concerning the whales on future levels of fish catches and this is e.g. reflected directly in 


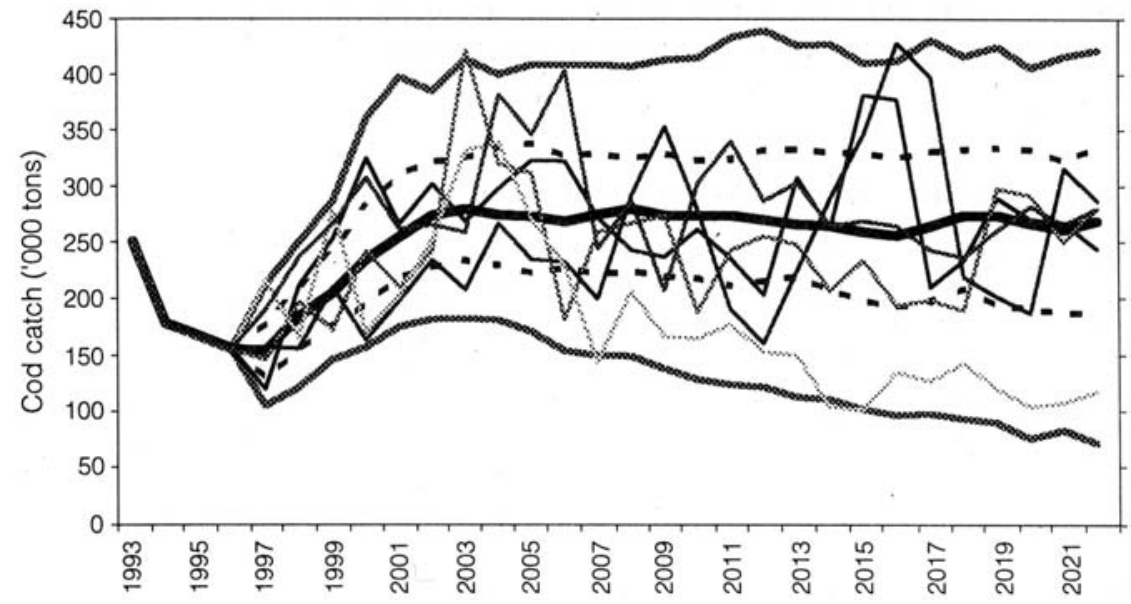

Fig. 6. Trend in cod catch in scenario A (base case; all predation set at base levels. Percentiles $(5 \%, 25 \%, 50 \%, 75 \%$ and $95 \%)$ shown as thick lines. Sample time trajectories shown as thin lines.

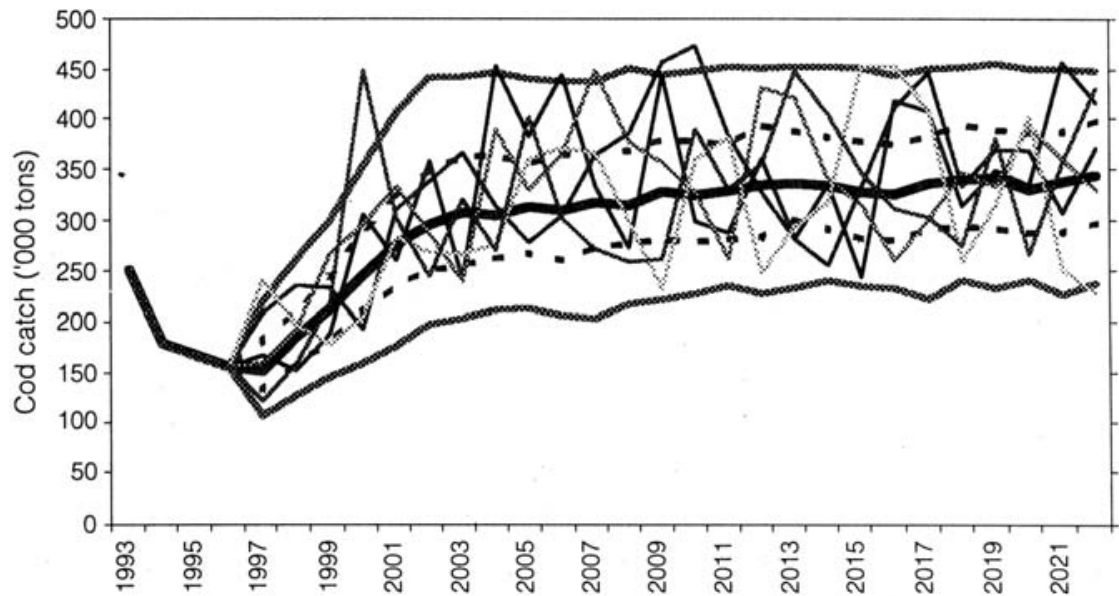

Fig. 7. Trend in cod catch in scenario D (alternative scenario; all marine mammals omitted). Percentiles (5\%, 25\%, 50\%, 75\% and 95\%) shown as thick lines. Sample time trajectories shown as thin lines.

comparisons between the averages obtained in scenarios A and D. This can therefore be thought of as a sensitivity test: how the future cod catch changes as a function of the consumption by minke whales, etc.

Another issue is how the uncertainty in the whale parameters is reflected as increased uncertainty in future prediction of fish catches. This is reflected in how the standard error in predictions changes as a result of changes in standard errors of whale parameters. This issue can be thought of as a question of what knowledge is important in order to reduce prediction variability.
In terms of the state of knowledge and importance of knowledge, it is seen that knowledge of the depletion level and of whether or not the minke whales consumes cod are the main factors affecting the variability in the medium-term prediction of cod yield.

\section{Summary}

Available data on the behavior and consumption of cetaceans off Iceland indicate that these animals include cod and capelin as a part of their diet. The present study has shown how this consumption can 
affect the results of predictions of future yields from the two fish stocks and the shrimp stock.

The point estimate of the effect of marine mammals on cod catches is a reduction by some 75000 tons, or over $20 \%$ and corresponding results are obtained for the capelin catches. There is considerable uncertainty associated with these numbers, however. The major components of this uncertainty are the potential increase in the whale stocks from their current size, and the diet of these predators. In particular, the assumed diet of minke and humpback whales is based on very limited data. Similarly, the estimates of absolute abundance of the marine mammals will affect the total predation and this directly affects the estimate of the fraction of natural mortality to be allotted to marine mammals rather than to other natural causes. Any revisions of these numbers will thus affect the point estimate of the influence on future harvests and must therefore be treated with some caution.

The uncertainty in the marine mammal parameters are seen to have a considerable effect towards increasing the uncertainty in future catch predictions for the fish catches. Thus, not only are future catches expected to become lower than if marine mammals are not included in the model, but the level of these catches also becomes more uncertain.

The predictions incorporate consumption by predators by assuming the predation mortality to be scaleable. Thus an increase in a marine mammal stock or the cod stock will influence the prey through a corresponding multiplicative increase in the natural mortality of the prey. The problem with the current approach is obviously that a fixed number of predators will consume an increasing and possibly unrealistic amount of prey as the prey abundance increase. Alternative models might include the predators catching a constant amount of prey, leading to increased prey mortality at low prey abundance. A problem with this particular alternative is that it becomes unrealistic to assume that a predator attempts to fill its diet of the prey at very low prey levels. In the present simulations the cod is only a small portion of the diet of the marine mammals and hence even a doubling of the size of the cod stock will not lead to excessive consumption by the marine mammals. There are some indications that predation of capelin by cod may follow a more complex relationship than the one used here (Magnússon and Pálsson, 1991). Testing the effects of such variations on the present assumptions would be an interesting area of future work.

The effects on the shrimp stock are of the second order, i.e. an increase in marine mammals would be predicted to lead to lower cod biomass, again leading to increased shrimp biomass. This type of effect is even more uncertain than the direct effects, many of which can be measured. Furthermore, it is quite possible that alternative models, even with minor deviations from the assumptions used here, may provide considerably different results in these second-order effects.

Interpretation of the results in this paper needs to be done with some care. The main focus has been on the difference between the case when whales are not included in the models and when they are included. Within the present model and in the case of increasing whale populations, this is equivalent to comparing the effect of the increase to predictions when the whale populations remain at a constant level.

The plotted biomass and catch trends tend to exhibit cyclic behavior. This sort of behavior comes about in several different ways, ranging from the direct effect of cyclic recruitment in the capelin stock (affecting cod growth), through the Ricker form of the stock and recruitment curve for cod to the predator-prey interactions where an increase in the cod stock will lead to a reduction in the capelin stock, which again leads to reduced cod growth. The existence of these model cycles invites some further investigation, particularly in order to elucidate whether they may appear in nature as well as in the models.

Despite all the uncertainties outlined above, this exercise indicates that cetaceans may have considerable effect on the yield of fish resources. Further research, aimed at reducing this uncertainty is therefore of great importance. In particular, studies on the diet of minke whales are needed to further elucidate the effects on the cod stock.

\section{References}

ALLEN, K. R. 1980. Conservation and management of whales. Washington Sea Grant, Seattle, 110 p.

ANON. MS 1991. Report of the ICES Multispecies Assessment Working Group. ICES C. M. Doc., No. Assess: 7 . 
MS 1994. Report of the ICES Multispecies Assessment Working Group. ICES C. M. Doc., No. Assess: 9.

MS 1995a. Nytjastofnar sjávar 1994/95 Aflahorfur fiskveidiárid 1995/96 (State of marine stocks in Icelandic waters 1994/95, prospects for the quota year 1994/96), Marine Research Institute Tech. Rep., No. 43.

MS 1995b. Report of the North-Western Working Group. ICES C. M. Doc., No. Assess: 19.

MS 1995c. Reports of the ICES Advisory Committee on Fishery Management, 1996. ICES Coop. Res. Rep.

MS 1995d. Report of the ICES Multispecies Assessment Working Group. ICES C. M. Doc., No. Assess: 3.

BALDURSSON, F. M., Á. DANÍELSSON, and G. STEFÁNSSON. (1996). On the rational utilization of the Icelandic cod stock. ICES J. Mar. Sci., 53: 643-658.

BOGSTAD, B., G. R. LILLY, S. MEHL, Ó. K. PÁLSSON, and G. STEFÁNSSON. 1994. Cannibalism and year-class strength in Atlantic cod (Gadus morhua) in Arcto-boreal ecosystems (Barents Sea, Iceland and Eastern Newfoundland). In: Cod and Climate Change. J. Jakobsson et al. (eds.) ICES Mar. Sci. Symp., 198: 576-599.

BOGSTAD, B., K. H. HAUGE and O. ULLTANG. 1997. A multispecies model for fish a marine mammals in the Barents Sea. J. Northw. Atl. Fish. Sci., 22: 317-341 (this issue).

DANÍELSSON, Á., G. STEFÁNSSON, F. M. BALDURSSON, and K. THORARINSSON. 1998. Utilisation of the Icelandic cod stock in a multispecies context. Marine Resource Economics, 12 (in press).

KATONA, S. K. and J. A. BEARD. 1990. Population size, migrations and substock structure of the humpback whale (Megaptera novaeangliae) in the western North Atlantic Ocean. Rep. Int. Whal. Comm., Special Issue, 12: 295-305.

MAGNÚSSON, K. G. and G. STEFÁNSSON. 1988. A feedback strategy to regulate catches from a whale stock. Rep. Int. Whal. Comm., Special Issue, 11: 171 .

MAGNÚSSON, K. G. and Ó. K. PÁLSSON. 1989. Trophic ecological relationships of Icelandic cod. ICES Rapp. Proc.-Verb., 188: 206-224.

MAGNÚSSON, K. G. and Ó. K. PÁLSSON. 1991. Predator-prey interactions of cod and capelin in Icelandic waters. ICES Mar. Sci. Symp., 193: 153-170.

MARTIN, A. R. and M. R. CLARKE. 1986. The diet of sperm whales (Physeter macrocephalus) captured between Iceland and Greenland. J. Mar. Biol. Assoc. U.K., 66: 779-790.

MITCHELL, E. 1975. Trophic relationships and competition for food in Northwest Atlantic whales. Proc.
Can. Soc. Zool. Ann. Meet.: 123-133.

PÁLSSON, Ó. K. 1983. The feeding habits of demersal fish species in Icelandic waters. Rit Fiskideildar, 7(1): $1-60$.

1994. A review of the tropic interactions of cod stocks in the North Atlantic. In: Cod and Climate Change. J. Jakobsson et al. (eds.) ICES Mar. Sci. Symp., 198: 553-575.

PÁLSSON, Ó. K. and G. STEFÁNSSON. (eds.) MS 1997. Bormicon. A boreal migration and consumption model. Marine Research Institute Tech. Rep., No. 58.

POPE, J. and L. WOOLNER, MS 1981. A simple investigation into the effects of predation on recruitment to some North Sea fish stocks. ICES C.M. Doc., No. $\mathrm{G}: 14$.

SIGURJÓNSSON, J. 1995. On the life history and autecology of North Atlantic rorquals. In: Whales, seals, fish and man. A. Schytte-Blix, L. Wallöe and Ö. Ulltang (eds.) Elsevier Science B.V., p. 425-441.

SIGURJÓNSSON, J. and A. GALAN. MS 1990. Information on stomach contents of minke whales in Icelandic waters. Scientific Committee of the IWC, Paper SC/42/NHMi28, 6 p.

SIGURJÓNSSON, J. and Th. GUNNLAUGSSON. 1990. Recent trends in abundance of blue (Balaenoptera musculus) and humpback whales (Megaptera novaeangliae) off west and southwest Iceland with a note on occurrence of other cetacean species. Rep. Int. Whal. Comm., 40: 537-551.

SIGURJÓNSSON, J. and G. A. VÍKINGSSON. 1997. Estimation of food consumption by cetaceans in Icelandic and adjacent waters. J. Northw. Atl. Fish. Sci., 22: 271-287 (this issue).

STEFÁNSSON, G. MS 1992. Notes on the stock-dynamics and assessments of the Icelandic cod. ICES C. M. Doc., No. G:71.

STEFÁNSSON, G., U. SKÚLADÓTTIR, and G. PÉTURSSON. MS 1994. The use of a stock production type model in evaluating the offshore (Pandalus borealis) stock of North Icelandic waters, including the predation of northern shrimp by cod. ICES C.M. Doc., No. K:25.

STEFÁNSSON, G. and B. Æ STEINARSSON. 1993. Um nylizun porsks. Ægir. (in Icelandic).

STEINARSSON, B. Æ. and G. STEFÁNSSON. MS 1991. An attempt to explain cod growth variability. ICES C.M. Doc., No. G:42.

VILHJÁLMSSON, H. 1994. The Icelandic capelin stockCapelin, Mallotus villosus (Muller) in the IcelandGreenland-Jan Mayen area. Rit Fiskideildar, 12(1): 1-281.

VÍKINGSSON, G. A and J. SIGURJÓNSSON. MS 1996. Feeding studies on the harbour porpoise (Phocoena phocoena) in Icelandic coastal waters. ICES C.M. Doc., No. N:7, 19 p. 